\title{
FELIPE POEY Y LOS ESTUDIOS SOBRE LA CIGUATERA
}

\section{Rosa M. González López}

Muchas disciplinas del saber humano se encuentran reflejadas en la obra escrita por Felipe Poey y Aloy (1799-1891), el mayor de los naturalistas cubanos del siglo XIX. Como investigador y docente expuso sus conocimientos en trabajos que van desde las investigaciones zoológicas especializadas hasta la elaboración de textos para la enseñanza de diferentes ciencias. Como hombre de amplia cultura y fino intelecto, su producción se vincula con la filología, ocupando en la literatura cubana un lugar destacado; pero, sin lugar a dudas, su labor más fecunda la desarrolló Poey en la ciencia que estudia los peces, donde los artículos por él escritos sobrepasan la cifra de los 50 publicados, esto sin contar su aún inédita Ictiología cubana. En el presente trabajo nos referiremos a sus estudios sobre la ciguatera.

Al estado de envenenamiento producido por la ingestión de pescado esporádicamente tóxico (1) dedicó Poey gran parte de su atención y de sus investigaciones ictiológicas. El resultado de sus primeros estudios lo dio a conocer en 1849, en un artículo sobre el tema incluido en su Revista zoológica de la isla de Cuba, y en 1861 cuando publicó en el Repertorio Físico-Natural de la isla de Cuba el trabajo: "Ciguatera. Memoria sobre la enfermedad ocasionada por los Peces venenosos».

Varios fueron los puntos que se propuso, si no esclarecer, por lo menos interpretar en términos científicos, a saber: determinar cuáles eran los peces sospechosos de trasmitir al hombre la enfermedad, averiguar seguidamente las causas que ocasionaban la misma en el pez, además de definir los síntomas característicos del mal, para así poder tomar las 
precauciones necesarias e idear, conociendo sus efectos, el método curativo más eficaz.

La propia ortografía de la palabra ciguatera, que designaba la enfermedad, resultó un problema por aclarar. Poey refería que los «literatos» de la isla, entre ellos Esteban Pichardo, autor de un diccionario de voces y frases cubanas, solían escribirla con $s$ por ser una voz empleada por los indios en tiempos del descubrimiento; pero él, que no tenía la prueba «de que los indios no cecearan» (2), como señalaba con ironía, prefería utilizar la ortografía del Diccionario de la Real Academia de la Lengua, aunque a la hora de designar la enfermedad en el hombre empleara la expresión provincial cubana enciguatado, en vez de aciguatado como proponía la asociación lingüística.

Otra de las razones que lo inclinaron a escribir la palabra ciguatera con $c$ tuvo que ver con la ortografía con que se escribía el nombre de un molusco llamado vulgarmente cigua (Cittarium pica), cuya ingestión ocasionaba en el hombre ciertos malestares y trastornos estomacales. Las personas que se veían afectadas al consumir la cigua se decían ciguatadas o enciguatadas, generalizándose posteriormente la palabra a los casos de indigestión, por así llamarlos, producidos por otros moluscos y por el pescado.

Como conclusión de sus observaciones dedujo que los peces de por sí no eran animales venenosos, aunque el hecho de que algunos ejemplares, ingeridos como alimento, causaran intoxicación le indujo a realizar una revisión de las obras de otros especialistas o entendidos en la materia, que, de una forma u otra, se referían ocasionalmente a las especies venenosas.

Poey analizó con detenimiento los criterios de Antonio Parra - posiblemente el primer autor que escribió en Cuba sobre la enfermedad-, incluidos en su libro Descripción de diferentes piezas de historia natural, las más del ramo marítimo, impreso en 1787; examinó la Historia general de los peces de Cuvier y Valenciennes, las investigaciones de Moreau de Jones (3) y Richard Hill (4) así como los estudios de toxicología del francoespañol Mateo Orfila (5). También utilizó una lista manuscrita de posibles peces ciguatos, elaborada por Pablo Lesmes, pescador de oficio y alcalde de mar (pesca) del barrio de San Lázaro, «hombre íntegro y honrado», al decir de Poey, y llegó a la conclusión de que las especies indicadas como venenosas eran unas 69 , sólo de peces, pues también otros mariscos (quelonios, crustáceos y moluscos) podían, aparentemente, provocar ocasionales envenenamientos al ser ingeridos.

Poey, sin embargo, redujo a diez las especies de peces propensos a 
transmitir la enfermedad, incluyendo entre ellos los siguientes: coronado (Seriola dumerili), picuda (Sphyraena barracuda), jurel (Caranx latus), jocú (Lutjanus jocu), cibi amarillo (Caranx barthulomaei), morena verde (Gymnothorax funebris), erizo o puerco espín (Diodon hystrix), tambor (Lagocephalus laevigatus), diablo (Ogcocephalus verspetilio) y jabón (Rypticus saponaceus).

Entrando ya en el campo de la etiología de la dolencia, Poey apuntó que no todos los peces enciguataban, ni todos los individuos catalogados como ciguatados causaban la muerte a quienes los ingirieran. Aunque el tamaño de los ejemplares no parecía relacionarse con el grado de su toxicidad, Poey advirtió que la mayoría de los peces ciguatos alcanzaban gran tamaño. El hábitat, por otra parte, no parecía determinante, pues en un mismo sitio había tantos ejemplares "sospechosos» como sanos, aunque -en términos generales- la patología se hallaba circunscrita al Mar de las Antillas y a otras zonas intertropicales.

Descartó totalmente que ciertos rasgos morfológicos fueran peculiares de los peces afectados; la presencia de la ciguatera no podía determinarse por el tamaño de la cabeza, la abertura bucal o la forma de los dientes (6), como pretendían algunos.

Durante el siglo XIX los conocimientos que sobre el origen de la ciguatera se tenían, apuntaban a posibles estados de envenenamiento o toxicidad del pescado. Se explicaba que la morbilidad provenía unas veces de que el pez hubiese comido los frutos de una planta llamada comúnmente manzanillo (Hippomane mancinella) (7), o cierta cantidad del cobre existente en los fondos marinos, así como también del que recubriría en forma de láminas los cascos de algunos buques. Los moluscos, zoófitos y las plantas marinas que figuraban en la dieta de varias especies y la indisposición del pez provocada por factores contaminantes del medio, como la turbulencia de las aguas en las bahías y fondos fangosos, se citaban a veces, igualmente, como causas del mal.

El naturalista, luego de valorar y objetar algunas de ellas, tenidas como verdades categóricas, entre la que se encontraba la atribuida al fruto del manzanillo, agregó sus propias conclusiones, estimando que el origen de la enfermedad debía buscarse en las lesiones que algunos helmintos podían ocasionar en las vísceras del animal, en sus necesidades insatisfechas en épocas de reproducción y en la falta de alimentos.

Una vez señaladas las causas que, en su opinión, provocaban la patología, hizo mención de aquellos signos que en el pez se revelaban -aparentemente- como resultado del trastorno funcional.

Entre los indicios mencionados por él estaban aquéllos que los pesca- 
dores de más experiencia le comunicaron. Señaló el enflaquecimiento del pez, la poca resistencia al curricán o para desprenderse del anzuelo una vez capturado, y la muerte rápida fuera del agua. Estaba Poey tan convencido de la primera de estas observaciones que llegó hasta recomendar a los consumidores no comer aquel pescado que a la vista se mostrara flaco, aunque fuera la especie de mayor confianza; reafirmando su parecer recordaba además el recurrido refrán cubano que decía: «estando la Picuda flaca, el que la come larga el pelon (8).

Parece que era de consenso entre la población de la época comprobar la toxicidad de un pescado - si éste se mostraba sospechoso- dándolo primero "a probar» a un animal. A esta práctica, recomendada como precaución ante la incertidumbre, se refería ya Antonio Parra. El doctor en Farmacia Cayetano Aguilera, profesor de la asignatura de química general en la Universidad de La Habana refirió a Poey sus experiencias de dar a comer huevas de manjuari, supuestamente venenosas (9), a una gallina.

Poey, por su lado, practicó en varias ocasiones y con distintas especies marinas experimentos similares:

«El gato es muy aficionado á esta clase de alimento, tanto que es aforismo jocoso que: si le pagan un salario en dinero, lo gasta en pescado, por lo que lo come de buena gana, crudo y cocido y como sus jugos gástricos no han sido creados para digerir la carne de estos animales, sino carne y huesos de ratas y conejos, sienten prontamente los efectos del envenenamiento, se enferman en alto grado y lo manifiestan con quejidos dolorosos que suelen terminar con la muerte» (10).

Otras precauciones que recomendó a los gastrónomos fueron: quitar las vísceras y limpiar bien el pescado antes de comerlo, ponerlo en salmuera con limón y vinagre antes de cocinarlo e ingerirlo, siendo indispensable procesarlo para el consumo en estado fresco: pues refería, citando a Moquín-Tandon, uno de los autores por él leído, que: «se ha dado el caso de que la mitad fresca de un pescado ha sido comida sin novedad, y la otra mitad, comida al otro día, ha dado funestos resultados» (11); hecho nada extraño si se admitía, con Poey, que la enfermedad de los peces ciguatos tal vez estaba determinada por un principio de descomposición de las sustancias que en la vida sana aparecían íntimamente unidas.

En otra parte de su «Memoria», al comentar los efectos que la ciguatera causaba en el hombre, afirmaba desconfiar de las descripciones de la enfermedad que daban algunos autores, porque, en su criterio, muy pocas 
habían sido recogidas por facultativos a la cabecera de los enfermos. No obstante ello, Poey se refirió a los síntomas que se admitían como más o menos generalizados entre los afectados de esta enfermedad: evacuaciones frecuentes, vómitos acompañados de náuseas con dolores de cabeza y articulaciones, fuertes cólicos, calambres, picazón sobre todo durante el período de convalescencia, y en algunos casos la caída del cabello y de las uñas.

Finalmente, sin ir más allá de los límites del conocimiento científico y de lo popular, recomendó como método terapéutico el zumo del limón, uno de los remedios más empleados en su época, "acreditado" muchos años antes por el portugués Antonio Parra, quien padeció la enfermedad, y aconsejado igualmente por los pescadores. También prescribió, tal y como lo recetaba el médico Mateo Orfila, un trozo de azúcar con diez o veinticinco gotas de éter sulfúrico.

Las regulaciones pesqueras, en época de Poey, en torno a la intoxicación conocida por ciguatera

La eficacia de las regulaciones pesqueras que regían en la isla, fue uno de los aspectos que Poey analizó en un artículo publicado en el tomo segundo del Repertorio Físico-Natural de la isla de Cuba, bajo el título de "Policía de la Pesca», el cual ya había anunciado en su estudio acerca de los peces ciguatos, como otro de los asuntos importantes que se desprendían de las investigaciones en torno al tema.

Su opinión favorecía el equilibrio entre la regulación administrativa y el conocimiento general que la población debía tener sobre los peces propensos a trasmitir la enfermedad. Su intención era velar, ante todo, por la salud de los consumidores sin afectar el desarrollo de la industria pesquera del país.

«No se me oculta - escribía- que del abuso no hay argumento contra el uso, ni de la infracción contra la ley, y que menor número de pescados sospechosos se introducirán con la prohibición que sin ella. Pero ya que el bien público es el fin propuesto, las cosas se han de considerar de otra manera. Mientras que la autoridad tome á su cargo el vigilar por la salud de todos, nadie cuida de sí mismo, ni aprende el vulgo á conocer los pescados ni trata de comerlos con las precauciones que aconseja la prudencia. La prohibición engendra la confianza ciega y el envenenamiento seguro. La Economía política nos enseña á cada rato que las leyes prohi- 
bitivas producen casi siempre un efecto contrario al que se proponen los legisladores» (12).

Históricamente las regulaciones de 1848, 1851 y 1855, esta última en su artículo 103, prohibían comercializar un elevado número de especies. La lista en vigor en ese último año incluía a unas veinte especies de peces. El análisis retrospectivo de estas ordenanzas hecho por Poey lo llevó a exponer, en mayo de 1856, una «Memoria sobre la ciguatera y los peces ciguatos» en la Sociedad Económica de Amigos del País. Este trabajo fue valorado favorablemente por el claustro de profesores de la Facultad de Medicina de la Universidad de La Habana, en un informe redactado por el prestigioso galeno Angel Cowley, muy ejercitado en los trabajos de salud pública por haber formado parte de las Juntas de Sanidad en la ciudad.

En septiembre de 1865, retomaba Poey el tema al solicitar al director de la administración pública que fuera revisada la lista de peces cuya expendición se prohibía y que se redujera su número a la mitad. El expediente confeccionado por las autoridades fue trasladado, para ser discutido en ese mismo año, a la Real Academia de Ciencias Médicas, Físicas y Naturales de La Habana, la cual debía emitir un juicio al respecto, en su condición de órgano de consulta para aquellas cuestiones donde se precisaran criterios científicos; pero dicha corporación no emitió ningún dictamen sobre esta cuestión hasta 1875, cuando un grupo de pescadores de la ciudad de Matanzas reclamó al gobierno colonial la modificación de las ordenanzas vigentes desde 1855 para el ramo de la pesca.

Sólo hubo en estos años un intento aislado de discutir la propuesta de Poey. Uno de los miembros de número de la Real Academia, Marcos de Jesús Melero, trató de romper el silencio en el cual, quizás intencionadamente, la institución científica había dejado la petición del naturalista. Melero, por iniciativa propia, elaboró en marzo de 1866 un juicio crítico acerca del trabajo «Memoria sobre la enfermedad ocasionada por los peces venenosos», impugnación que quedó recogida en el trabajo "Ideas peregrinas», el cual nunca llegó a publicarse en los Anales de la corporación, pues encerraba severas críticas a la obra del ictiólogo cubano.

Cuando Poey escribió la «Memoria» y el trabajo denominado «Policia de la Pesca», pretendía obviamente dar a conocer sus criterios científicos sobre el delicado asunto de los peces ciguatos; pero en su ánimo se hallaba, además, el propósito de liberar a los consumidores de restricciones que estimaba excesivas, y a la vez defender a quienes ganaban su sustento en las faenas de la pesca. Esta inclinación no fue pasada por alto en la 
impugnación de Melero, opuesto a cualquier «mediatización» con fines sociales de los hechos que consideraba estrictamente científicos.

Era evidente la simpatía de Poey por los pescadores, trabajadores que vivían en la mayor pobreza, a quienes llamaba «hombres esforzados y de manos callosas», que se lanzaban en socorro de los náufragos, con más «garbo que los elegantes en los salones iluminados por el gas y regocijados por la orquesta» (13). Estas simpatías las interpretaba Melero como la causa de que Poey fuera "propenso a incurrir en equivocaciones, suposiciones, errores científicos y de apreciación, á pesar de sus 40 años de experiencia» (14).

Sin embargo, tan gratuita acusación no pudo ser adecuadamente sustentada por Melero. Para afirmar que Poey tergiversaba los datos en favor de los pescadores, debía demostrar inequívocamente no que Poey simpatizara con ellos, sino que sus datos eran incorrectos; pero en su trabajo no hay nada que intente siquiera un estudio de las especies en cuestión, y las conclusiones de su impugnación parten del argumento de que - a falta de conocimientos seguros- era preferible conservar las prohibiciones de expendición tal cual aparecían en las ordenanzas. Melero se manifestó como defensor de la autoridad del gobierno en materias de salud pública, presuntamente amenazadas por los partidarios del laissez faire:

«...digan lo que quieran los que interpretando erróneamente las sanas doctrinas económicas piensan que la Economía política es capaz de negar la intervención de la Autoridad para impedir el comercio de artículos de consumo necesarios á la salud...» (15).

Casi una década medió entre la refutación de Melero y la constitución oficial de una comisión académica que debería estudiar y realizar experimentalmente las investigaciones sobre la ciguatera y los peces propensos a trasmitirla. El 26 de septiembre de 1875, Poey, Francisco Adolfo Sauvalle, Joaquín Francisco Lastres, Fernando González del Valle, Rafael Cowley y el propio Melero eran los miembros propuestos para emprender los estudios y aconsejar al gobierno si procedía hacer o no la reforma solicitada por los pescadores matanceros. Las.investigaciones a escala experimental nunca se hicieron, y aun debían transcurrir cinco años más para que la Real Academia de Ciencias Médicas, Físicas y Naturales de La Habana emitiera su veredicto definitivo.

El 9 de mayo de 1880, en sesión ordinaria de trabajo, era leído un informe de Juan Vilaró, el cual en muchos de los puntos coincidía con los 
trabajos de Poey. Sus propuestas se concretaban a indicar cómo debía quedar redactado el artículo 103 de las Ordenanzas Municipales. Propuso la prohibición de 15 peces (16) de los 20 contenidos en la lista de 1855, y la destrucción de éstos si eran localizados en los mercados públicos, con la consiguiente multa al infractor. Su informe, empero, fue cuestionado por uno de los médicos asistentes a la reunión académica en estos términos:

«...es muy importante - decía Rafael Cowley-, pero bajo otro punto de vista, no el de la Higiene, que reclama observaciones que no existen allí, observaciones recogidas con todas las garantías científicas, toda vez que la opinión de los profanos no es capaz de constituir dictamen Académico» (17).

El 11 de julio, después de largas horas de análisis donde intervinieron, entre otros, los doctores Carlos J. Finlay, Antonio Mestre, José Rafael Montalvo, José Pantaleón Machado y el propio Rafael Cowley, la corporación emitía su fallo:

«...no habiendo datos científicos suficientes, ni observaciones ni experimentos bastantes para decidir acerca de la naturaleza de la ciguatera y de cuáles sean los peces realmente ciguatos, la Academia no cree que deba por hoy alterarse la lista de dichos peces formada por el Municipion (18).

Aunque, en efecto, en aquella época la naturaleza de la ciguatera se hallaba envuelta en la mayor bruma, hay que reconocer hoy la perspicacia científica de Poey y el valor que él atribuyera a las observaciones de los propios pescadores. Durante los últimos años del siglo XIX los conocimientos sobre la intoxicación producida por el llamado «pescado ciguato» tuvo en Cuba poco desarrollo; las investigaciones a escala de laboratorio comenzaron en realidad en 1900, cuando el médico higienista Juan Nicolás Dávalos vinculó a ellas sus estudios bacteriológicos.

En cuanto a regulación pesquera se refiere, en 1929 la prohibición de venta se limitó a cuatro especies de peces, coronado, picúa - de más de tres libras-, jurel y bonací; en 1936 la lista se redujo a una sola, la picúa; y en 1956 se dispuso prohibir la venta y transporte de las especies conocidas como picúa, coronado, bonací gato, tambor y morena prieta. La regulación vigente prohibe consumir como alimento un total de 18 especies, de las cuales, a juicio de los especialistas (19), sólo ocho son induda- 
blemente causantes circunstanciales de ciguatera en Cuba. Estas son: aguají, arigua, bonací gato, tiñosa, coronado de ley, jurel o gallego, picúa (llamada picuda por Poey) y morena verde. Las subrayadas fueron mencionadas por Poey.

\section{NOTAS}

(1) En un reciente artículo que resume el estado actual de las investigaciones sobre la ciguatera: ANDERSON, D. H. y P. S. LoBE (1987): «The continuing enigma of ciguatera». Biological Bulletin, Vol. 172, p. 89-107, se admite que ésta es una intoxicación causada por peces que ingieren "ciguatoxinas" con su alimento. Aunque no hay todavía una certeza absoluta al respecto, parece ser que estas toxinas son producidas por varios dinoflagelados bentónicos, -el primero estudiado desde 1977 fue Gambierdiscus toxicus - Al ser ingeridos por peces, la toxina se conserva en éstos y se trasmite al hombres que los consume. La ciguatoxina en sí parece ser un ácido graso de cadena larga altamente oxigenada, y está asociada en algunas especies con otras toxinas que, en algunos casos, producen síntomas similares a los de la ciguatera.

(2) Poey, Felipe (1966): «Ciguatera. Memoria sobre la enfermedad ocasionada por los Peces venenosos». Repertorio Físico-Natural de la isla de Cuba, tomo II, p. 1.

(3) El trabajo de este autor, al cual Poey hace mención fue: «Recherches sur les Poissons toxicophères des Indes occidentales». Nouveau Journal de Médecine. Tomo XI. París, 1822.

(4) Consultó el trabajo «Poisonous Fishes», publicado por este autor en Journal of Spanish Town, Jamaica, 1857.

(5) Para una biografía de Mateo Orfila acompañada de una antología de sus libros de texto, ver la obra de Rafael Huertas Garcia-Alejo (1988): Orfila, saber y poder médico, publicada en Madrid, por el Consejo Superior de Investigaciones Científicas.

(6) Sobre esta opinión Felipe Poey hizo una rectificación importante en: «Ciguatera. Memoria sobre la enfermedad ocasionada por los Peces venenosos». (Repertorio Físico-Natural de la isla de Cuba. Tomo II, 1866, p. 33). Refiriéndose al pez conocido vulgarmente como picuda escribió:

\footnotetext{
«Algunos creen que la base de los dientes ennegrece en dicho pez ... esta última opinión la da Cuvier como mía en su Historia de los Peces, tomo 3, pag 341; pero yo no se la he afirmado; le he referido solamente el modo de pensar de algunos pescadores".
}

Las investigaciones recientes confirman que no hay caracteres morfológicos que identifiquen inequívocamente que un pez «está ciguato». Entre los rasgos que el folklore ha atribuido a los peces enfermos están, entre otros: coloración diferente a los peces normales, sabor agrio de la carne, olor característico, estómagos dilatados, secreción mucosa en las agallas, carne verdosa, etc. (Nellis, D. W. y Barnard, G. W. (1986): Ciguatera. A legal and Social Overview. Marine Fisheries Review, Vol. 48. N.o 4, p. 2-5).

(7) La opinión sobre los efectos venenosos del llamado manzanillo, pudiera atribuirse a José Martín Félix de Arrate, quien en una ocasión escribió:

"...en cierta estación del año es preciso no usar de los pargos grandes por el peligro de las
ciguateras, que son muy nocivas y se originan de haber comido una fruta llamada manzanillo 
que tiene calidad tan venenosa que aun después de muerto, cocido y compuesto el pez, ocasiona al que toma su carne, vómitos, evacuaciones y otros accidentes muy temibles..."

Arrate, José Martín Félix de (1876): Llave del Nuevo Mundo antemural de las indias occidentales. La Habana descriptiva: noticias de su fundación, aumento y estado. En: CowLEY, RafaEL: Los tres primeros historiadores de la isla de Cuba. Edición Rafael Cowley y José Pego, La Habana, p. 148.

(8) «Ciguatera. Memoria sobre la enfermedad ocasionada por los Peces venenosos». En: Repertorio Físico-Natural de la isla de Cuba, tomo II, 1866, p. 11.

(9) Sobre este particular escribió Poey:

\begin{abstract}
"Ya yo sabia por el Sr. Pbro. D. Ramón de la Paz y Morejón que las huevas de este pescado (manjuarí) son venenosas, sin embargo de ser su carne buena y sana. El Dr. D. Cayetano Aguilera me ha confiado este dato: dió á comer las huevas á dos gallinas; las cuales á las dos horas cayeron muertas, como invadidas de estupor ó borracheran.
\end{abstract}

Op. cit., p. 23.

(10) Op. cit., p. 5.

(11) Op. cit., p. 35.

(12) Poey, FeliPe (1866): «Policía de la Pesca». Repertorio Físico-Natural de la isla de Cuba, tomo II, p. 63

(13) Op. cit., p. 65 y 66

(14) Melero, Marcos de Jesús: «Ideas peregrinas», manuscrito fechado el 8 de marzo de 1866. (Papeles de Marcos de Jesús Melero en el Archivo Histórico del CEHOC).

(15) Ibidem.

(16) Los peces propuestos por Juan Vilaró fueron: jocú, jurel, tiñosa, cibío amarillo, coronado, y picuda, cuando pasaran de tres libras; aguaji, bonací gato, bonací cardenal y cubera, cuando pasaran de seis libras: morena verde, rizo, tamboril, jabón y diablo, en todas sus edades.

(17) «Rectificación a la lista de los peces ciguatos». Anales de la Real Academia de Ciencias Médicas, Físicas y Naturales de La Habana, tomo XVII, 1880, p. 115.

(18) Op. cit., p. 121

(19) Comunicación personal brindada por el licenciado Emilio García quien nos informó la existencia de una Carta Circular (N.o 14) con fecha 25 de mayo de 1987 del Ministerio de la Pesca de Cuba, donde se regula para el consumo de la población una serie de especies de peces por considerarlas ciguatas. 